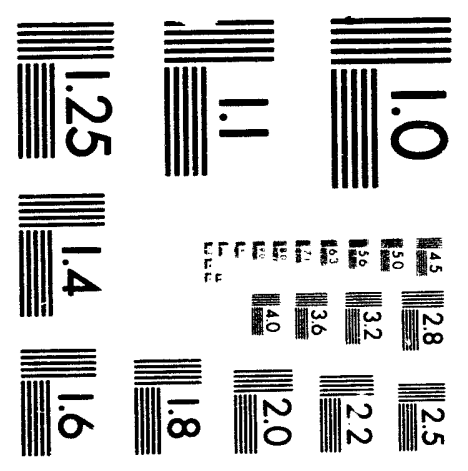




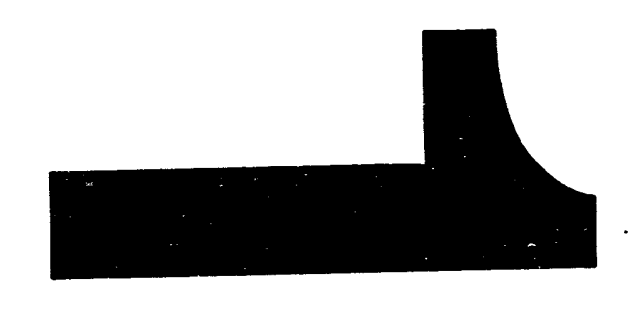

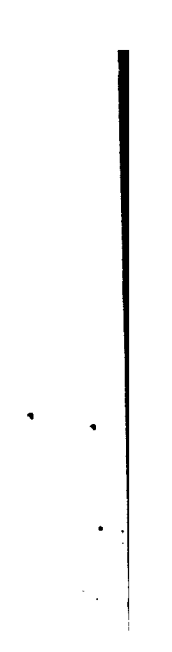
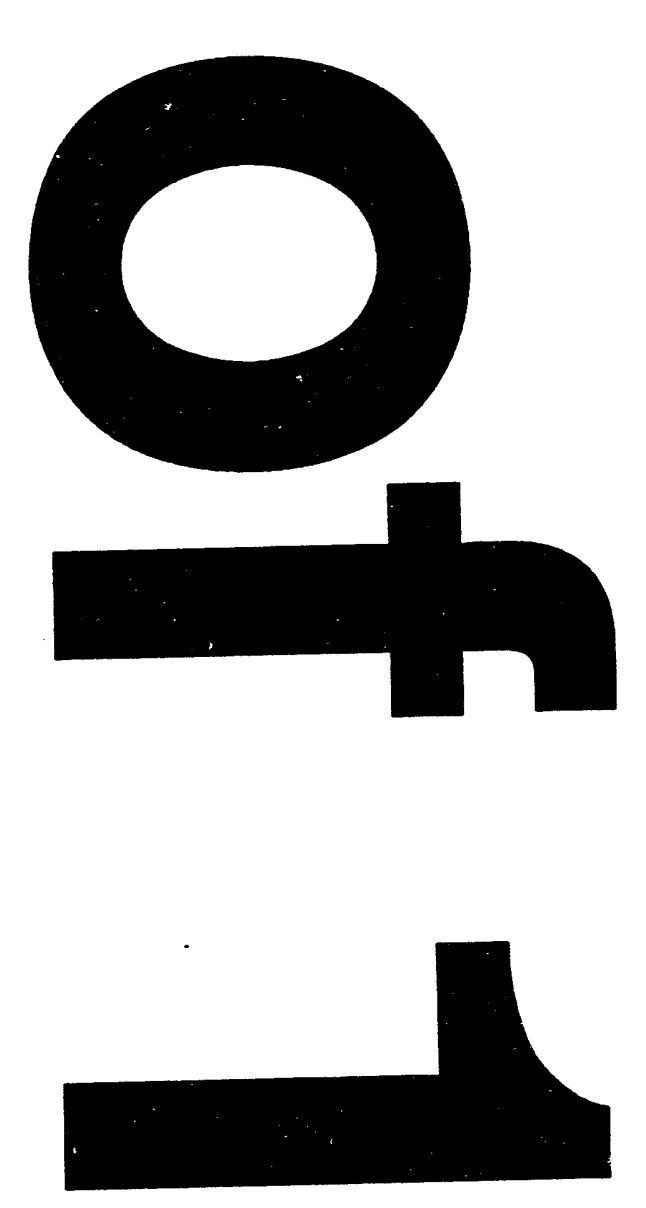
SAND93-2007 • UC-411

Unlimited Release

Printed October 1993

\title{
INFLUENCE OF LATTICE DAMAGE ON RETENTION AND TRANSPORT OF DEUTERIUM IN BETA SILICON CARBIDE
}

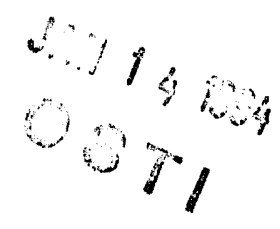

\author{
William R. Wampler \\ and \\ Rion A. Causey \\ Sandia National Laboratories
}

\begin{abstract}
Experiments were done to determine the effect of lattice damage on solubility and transport of deuterium (D) in silicon carbide. Beta $\mathrm{SiC}$ samples were irradiated with energetic ions to produce lattice damage, and were then soaked in $D_{2}$ gas at $1000^{\circ} \mathrm{C}$. The concentration of $D$ versus depth was then measured by nuclear reaction analysis. Very near the surface $(<0.5 \mu \mathrm{m})$ the concentration of $D$ was larger in the irradiated samples than in the unirradiated material, but beyond $1 \mu \mathrm{m}$ the D concentrations were similar ( $20 \pm 10$ atomic $\mathrm{ppm})$, even though the damage extended to $2.2 \mu \mathrm{m}$ in most of the samples. The results from this study of ion irradiated $\mathrm{SiC}$ together with our previous study of tritium migration in undamaged $\mathrm{SiC}$ point to the conclusion that uptake of $\mathrm{D}$ from gas into $\mathrm{SiC}$ occurs by transport along grain boundaries, whereas uptake of $D$ into lattice damage produced by ion irradiation, and release of energetically implanted $D$ both require permeation of $D$ within grains which is much slower
\end{abstract}

MASTER 


\section{Introduction}

Vapor deposited beta silicon carbide has been proposed as a permeation barrier to contain tritium within microspheres in a tritium production reactor. For this application it is important to know the solubility and diffusivity of tritium in $\mathrm{SiC}$. A study of these properties was described in a previous report [1]. A conclusion from that study was that the solubility and transport were dominated by a small concentration of strong trap sites possibly due to dangling bonds at grain boundaries. The question arises whether neutron irradiation in a reactor will increase the concentration of trap sites and thereby change the transport of tritium through the film. Energetic particle bombardment causes atomic displacements in the $\mathrm{SiC}$ crystal lattice creating dangling bonds which could increase the concentration of traps for tritium. An increase in the concentration of traps is expected to increase the apparent solubility and decrease the apparent diffusivity of tritium, which could affect breakthrough times for permeation in a reactor environment. The purpose of the experiments described here is to determine the effect of energetic particle bombardment on the number of traps and the apparent solubility of tritium in $\mathrm{SiC}$ so that the influence of neutron irradiation on tritium permeation can be anticipated.

\section{Experimental Procedures}

The experimental method used here is similar to the one used in an earlier study of the influence of lattice damage on $\mathrm{D}$ retention in graphite [2]. In both studies lattice damage was produced by energetic ion irradiation. In the study described here, samples of vapor deposited $\beta$ $\mathrm{SiC}$ were bombarded with helium and hydrogen ions at energies of $0.33 \mathrm{MeV}$ and $1 \mathrm{MeV}$ to various doses to produce lattice damage up to several displacements per atom (DPA) at depths up to $2.2 \mu \mathrm{m}$. The samples were then soaked in deuterium (D) gas at $1000^{\circ} \mathrm{C}$ to allow deuterium to occupy the traps. The concentration of $\mathrm{D}$ in the $\mathrm{SiC}$ was then measured by nuclear reaction analysis (NRA).

Deuterium was used in this study, rather than tritium, to avoid the experimental complication of handling radioactive material, and to make use of the well established experimental technique of measuring $\mathrm{D}$ depth profiles by NRA. Conclusions from this study with $\mathrm{D}$ also apply to tritium since the effect of the isotopic difference on solubility and diffusivity is small.

\subsection{Material}

The SiC used in this study was produced at General Atomics by chemical vapor deposition (CVD) at $1550^{\circ} \mathrm{C}$ onto a graphite substrate at a deposition rate of $0.3 \mu \mathrm{m} /$ minute. The SiC was removed from the substrate after deposition [1]. Sample dimensions were $4 \times 5 \mathrm{~mm}$ and 60-70 $\mu$ 
$\mathrm{m}$ thick. The material was beta (cubic) $\mathrm{SiC}$ as shown by $\mathrm{X}$-ray diffraction. The measured density of the material was 3.21 to $3.22 \mathrm{gm} / \mathrm{cm}^{3}$, close to the expected value of $3.217 \mathrm{gm} / \mathrm{cm}^{3}$ for $\mathrm{SiC}$. The grain size was about $1 \mu \mathrm{m}$ at the substrate side increasing to a few $\mu \mathrm{m}$ at the opposite side.

\subsection{Lattice Damage by Ion Implantation}

$\mathrm{SiC}$ samples were bombarded with helium and hydrogen ions at energies of $0.33 \mathrm{MeV}$ and 1 $\mathrm{MeV}$ to various doses to produce lattice damage up to several displacements per atom (DPA) at depths up to $2.2 \mu \mathrm{m}$. Table 1 summarizes the various implantations used. The entire sample surface was covered by the ion bombardment, and a rastered beam was used to insure a uniform dose over the sample surface. The beam dose was determined from charge integration during the ion bombardment.

The Monte Carlo particle transport code TRIM [4] was used to calculate the depth profiles of the damage and concentration of implanted atoms. Figure 1 shows a TRIM calculation of the damage and He concentration versus depth produced by implanting $1 \mathrm{MeV} \mathrm{He}^{+}$ions to a dose of $10^{17} \mathrm{He} / \mathrm{cm}^{2}$ into SiC. This implantation produces $\sim 3.5 \mathrm{DPA}$ of damage strongly peaked near the end-of-range (EOR) at a depth of $2.2 \mu \mathrm{m}$, and a much lower damage of $\sim 0.1 \mathrm{DPA}$ at depths less than $1 \mu \mathrm{m}$. The peak He concentration from this implant is $\sim 6$ atomic $\%$ at a depth of $2.25 \mu \mathrm{m}$. Table 1 summarizes the results from TRIM calculations for the various ion irradiations. The table gives the depth at which the implanted particles come to rest (EOR) which is also near the depth at which the most damage is produced as shown in figure 1. Table 1 also gives the amount of damage produced near the surface and near the EOR, and the peak concentration of the implanted particles. Although the $\mathrm{H}$ and $\mathrm{He}$ may be trapped at lattice defects produced during their implantation, the fact that each implanted atom creates many defects means that most of the defect sites should not be affected by the $\mathrm{H}$ or He. Throughout this work, units of atomic ppm, atomic $\%$ and DPA refer to the total atomic density of Si and $\mathrm{C}$ atoms of $0.97 \times 10^{23}$ atoms $/ \mathrm{cm}^{3}$.

Microstructural analysis of lattice damage produced by $\mathrm{He}$ ion irradiation has been reported by Nakata et. al. [5] and by Hojou et.al. [6]. Using cross-sectional transmission electron microscopy Nakata et. al. have shown that irradiation of $\mathrm{SiC}$ at room temperature with $400 \mathrm{keV}$ He ions to a dose of $10^{16} \mathrm{He} / \mathrm{cm}^{2}$ produced an amorphous layer $0.1 \mu \mathrm{m}$ wide at the EOR. An adjacent layer containing defect clusters was also observed. Accordingly, in our experiments, samples SIC6, SIC12, SIC13 and SIC14 probably formed an amorphous layer during the He ion irradiation. Hojou et.al. found that the amorphous structure formed by $\mathrm{He}$ ion irradiation at room temperature was recrystalized by annealing at $800^{\circ} \mathrm{C}$. Thus, in our experiments, the amorphous layer should recrystalize during the subsequent heating to $1000^{\circ} \mathrm{C}$ for the $\mathrm{D}_{2}$ gas exposure. 
Table 1 Summary of sample preparation.

\begin{tabular}{|l|l|l|l|l|l|l|l|l|}
\hline Sample & Ion & $\begin{array}{l}\text { Dose } \\
\left(\mathrm{nm}^{-2}\right)\end{array}$ & $\begin{array}{l}\text { Energy } \\
(\mathrm{MeV})\end{array}$ & $\begin{array}{l}\text { Range } \\
(\mu \mathrm{m})\end{array}$ & $\begin{array}{l}\text { DPA } \\
\text { Surface }\end{array}$ & $\begin{array}{l}\text { DPA } \\
\text { EOR }\end{array}$ & $\begin{array}{l}\text { Peak } \\
\text { Concentration } \\
(\text { at. \% })\end{array}$ & $\begin{array}{l}\mathrm{D}_{2} \text { Soak } \\
\text { time } \\
(\mathrm{hrs})\end{array}$ \\
\hline SIC17 & $\mathrm{D}$ & 20 & .06 & 0.5 & .003 & .02 & 0.2 & None \\
\hline SIC14 & $\mathrm{He}$ & 1000 & 1 & 2.2 & 0.1 & 3.5 & 6 & 48 \\
\hline SIC13 & $\mathrm{He}$ & 1000 & 1 & 2.2 & 0.1 & 3.5 & 6 & 48 \\
\hline SIC12 & $\mathrm{He}$ & 100 & 1 & 2.2 & .01 & .35 & 0.6 & 64 \\
\hline SIC9 & $\mathrm{H}$ & 100 & 0.33 & 2.1 & .001 & .03 & 0.6 & 48 \\
\hline SIC8 & $\mathrm{He}$ & 20 & 1 & 2.2 & .002 & .07 & 0.12 & 48 \\
\hline SIC7 & $\mathrm{H}$ & 10 & 0.33 & 2.1 & .0001 & .003 & 0.06 & 48 \\
\hline SIC6 & $\mathrm{He}$ & 400 & 0.33 & 1 & 0.1 & 1.5 & 3 & 16 \\
\hline SIC3 & None & & & & & & & 45 \\
\hline
\end{tabular}

* Annealed $1400^{\circ} \mathrm{C} 1$ hour after He implant and before $\mathrm{D}_{2}$ gas exposure. 


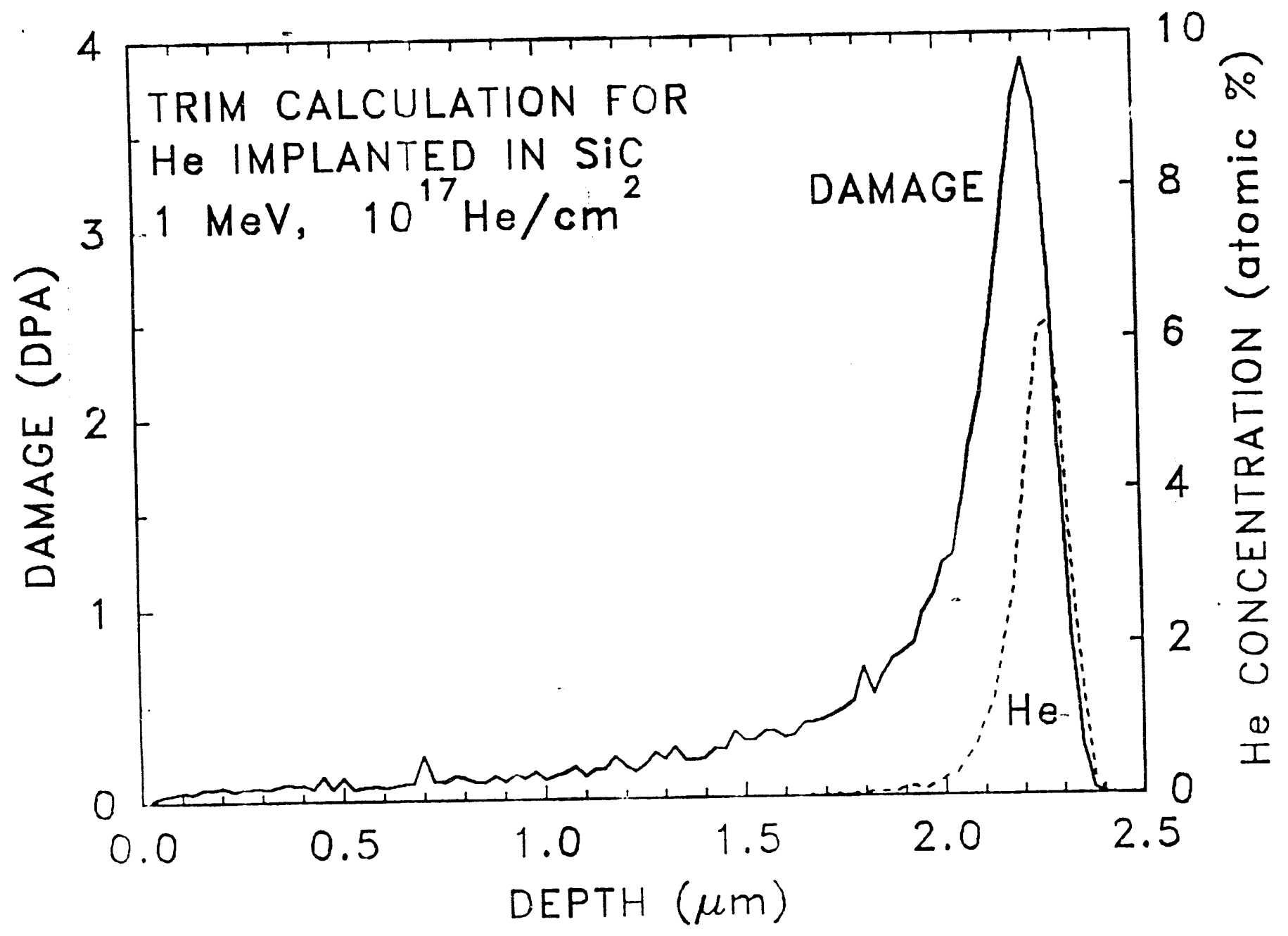

FIGURE 1 TRIM calculation of the displacement damage (solid line) and concentration of He (dashed line) versus depth produced by implantation with $1 \mathrm{MeV} \mathrm{He}^{+}$ions to a fluence of $10^{17} \mathrm{~cm}^{2}$, conditions corresponding to samples SIC13 and SIC14. 
One of our samples (SIC13) was annealed in vacuum at $1400^{\circ} \mathrm{C}$ for one hour after the $\mathrm{He}$ implant. It has been shown previously [7] that heating at $1400^{\circ} \mathrm{C}$ causes precipitation of implanted He into small bubbles, and some recovery of lattice damage is also likely. The purpose of this anneal was to determine whether the change in microstructure produced by annealing at $1400^{\circ} \mathrm{C}$ would affect hydrogen retention.

Another sample (SIC17) was implanted with $2 \times 10^{15} \mathrm{D} / \mathrm{cm}^{2}$ at $60 \mathrm{keV}$ producing a peak D concentration of about 0.2 atomic $\%$ at a depth of $0.5 \mu \mathrm{m}$. This sample was used to study the thermal release of $\mathrm{D}$ implanted into $\mathrm{SiC}$. This technique has been used in metals [8] and semiconductors [9] to determine the binding energy of $D$ to traps produced by ion irradiation.

\subsection{Gas Exposure}

Following ion irradiation, the $\mathrm{SiC}$ samples were exposed to $\mathrm{D}_{2}$ gas at $1000^{\circ} \mathrm{C}$ and 650 Torr for the times indicated in table 1. Based on our previous determination of diffusivity and solubility of hydrogen in undamaged $\mathrm{SiC}$ [1], these conditions should allow sufficient permeation of $\mathrm{D}$ through the $\mathrm{SiC}$ to reach equilibrium between the gas and trap sites present in the lattice to a depth of a several $\mu \mathrm{m}$, assuming isotropic bulk diffusion.

Exposures were done inside a quartz tube which was evacuated with an ion pump prior to backfilling with $\mathrm{D}_{2}$ gas $(99.97+\%$ pure) to the desired pressure. During the exposure the temperature was monitored with a chromel-alumel thermocouple and gas pressure was monitored with a capacitance manometer. Initial cooling rates at the end of the exposures were $\sim 2^{\circ} \mathrm{C} / \mathrm{sec}$, giving cool-down times short compared to the exposure durations.

\subsection{Measurement of Deuterium Concentration by Nuclear Reaction Analysis}

Nuclear reaction analysis was used to measure the concentration of D versus depth in the SiC. This is done by using an analysis beam of ${ }^{3} \mathrm{He}^{+}$ions from a Van de Graaff ion accelerator. The size of the beam spot was $2 \times 2 \mathrm{~mm}$. The analysis beam spot was entirely within the implanted area on the samples. Some of the ions undergo the $D\left({ }^{3} \mathrm{He}, \mathrm{p}\right) \alpha$ nuclear reaction with $\mathrm{D}$ atoms in the target giving energetic protons which are counted using a silicon charged particle detector. The yield of protons was measured for various incident ${ }^{3} \mathrm{He}$ energies between 0.3 and $2 \mathrm{MeV}$. The NRA data taken for sample SIC14 is shown in figure 2 as an example. From this data the D concentration versus depth can be determined. This is possible because the ${ }^{3} \mathrm{He}$ ions lose energy as they penetrate deeper into the target, which means that higher energy analysis beams detect $D$ at greater depths. Since the nuclear reaction cross section [10] and stopping power [4] are known, the data can be numerically deconvoluted to give the concentration of $D$ versus depth. 


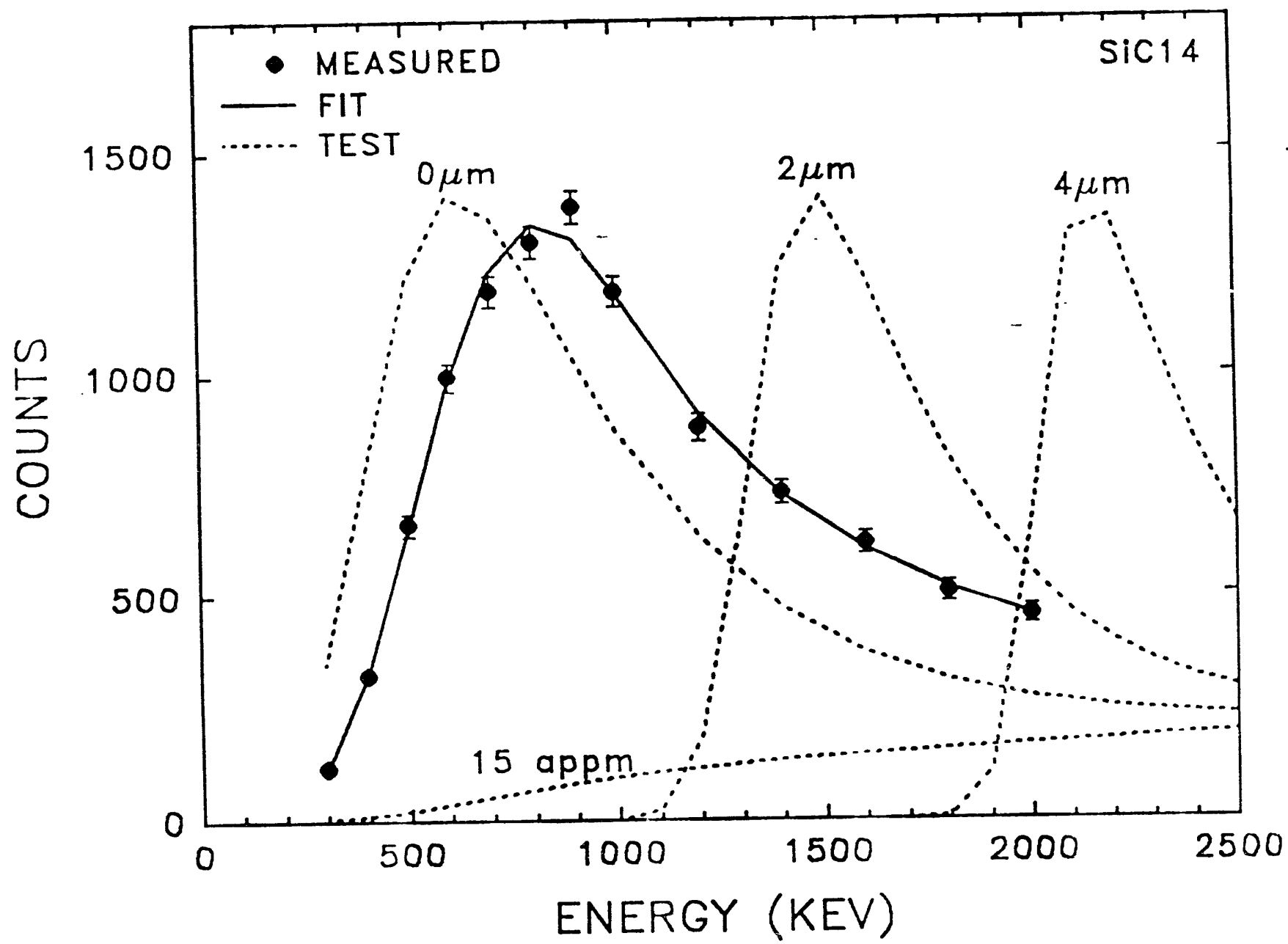

FIGURE 2 Number of protons counted versus analysis beam energy for sample SIC14 (dots), and the fit (solid line) from the deconvolution used to determine the $D$ concentration versus depth. The dashed lines show yields calculated for $1.5 \times 10^{1.5} \mathrm{D} / \mathrm{cm}^{2}$ on the surface and at 2 and 4 um beneath the surface, and for a uniform concentration of 15 appm. 
The mathematical procedure used for the deconvolution is described in reference 11. The solid line in figure 2 shows the fit to the data for SIC14.

To illustrate the sensitivity and depth resolution of the NRA, figure 2 also shows yields calculated for several test cases including delta function distributions of $\mathrm{D}$ at the surface and at 2 and $4 \mu \mathrm{m}$ beneath the surface, and for a uniform $\mathrm{D}$ concentration of $15 \mathrm{appm}$. The curve for the case of $D$ on the surface shows the energy dependence of the nuclear reaction cross section which has a broad peak near $600 \mathrm{keV}$ and decreases at higher energies [10]. Figure 3 shows the D concentration versus depth obtained from the fit shown in figure 2 for SIC14, and the D concen ${ }^{4}$ rations from similar fits to data from all the other samples. This method enables D concentrations as small as one atomic part per million to be measured to a maximum depth of about $4 \mu \mathrm{m}$ with a depth resolution of few tenths of a $\mu \mathrm{m}$. Surface coverages as small as $10^{13} \mathrm{D} / \mathrm{cm}^{2}$ can be measured.

In addition to the nuclear reaction analysis of $\mathrm{D}$, each sample was analyzed by Rutherford backscattering spectroscopy (RBS). The RBS analysis served the dual purpose of making sure the analysis beam was centered on the sample, and analyzing the near-surface composition for possible contaminants. Surface contamination by metal impurities was low, typically $<2 \times 10^{15}$ atoms $/ \mathrm{cm}^{2}$ except on sample SIC13 which had $1.2 \times 10^{17} / \mathrm{cm}^{2}$ of molybdenum. This molybdenum was present at a concentration of about 6 atomic $\%$ extending to a depth of about $0.2 \mu \mathrm{m}$. This molybdenum contamination probably occurred during the vacuum anneal at $1400^{\circ}$. The RBS also showed the SiC contained iron at a concentr tion of 0.3 atomic $\%$ to a depth greater than $0.4 \mu \mathrm{m}$ from the surface.

\section{Discussion}

\subsection{Solubility and Diffusivity of $\mathrm{D}$ in Undamaged $\mathrm{SiC}$ and the Effect of Traps}

Two significant features which emerged from our previous study of tritium and deuterium in undamaged $\mathrm{SiC}$ [1] were the small but exothermic solubility $S$ and the very low diffusivity $\mathrm{D}_{\mathrm{f}}$ which are given by

and

$$
\mathrm{S}=\mathrm{S}_{\mathrm{o}} \exp \left(-\mathrm{Q}_{\mathrm{S}} / \mathrm{kT}\right)
$$

where $\mathrm{S}_{\mathrm{O}}=8.2 \times 10^{15}$ atoms $\mathrm{cm}^{-3} \mathrm{~atm}^{-1 / 2}, \mathrm{QS}_{\mathrm{S}}=-0.61 \mathrm{eV}, \mathrm{D}_{\mathrm{O}}=9.8 \times 10^{-4} \mathrm{~cm}^{2} \mathrm{~s}^{-1}$ and $\mathrm{QD}=1.89 \mathrm{eV}$. According to equation 1 , the concentration of $\mathrm{D}$ in $\mathrm{SiC}$ in equilibrium with $\mathrm{D}_{2}$ gas at pressure $\mathrm{P}$ is

$$
C=P^{1 / 2} S \text {. }
$$


Here we assume that tritium and deuterium have the same solubility and diffusivity in SiC. The fact that the solubility is small but has an exothermic, i.e. negative, heat of solution indicates that the number of sites at which deuterium can reside is small compared to the number of host atoms in the $\mathrm{SiC}$ lattice. The observed solubility must therefore be due to a relatively small number of sites, which we refer to as traps. In this situation the apparent heat of solution $Q_{S}$, is the activation energy for populating traps from the gas phase, which is equal to the energy required to break the D-D bond (2.26 eV/atom) minus the binding energy $\mathrm{Q}_{\mathrm{T}}$ of a D atom to a trap. The measured value of $\mathrm{QS}_{\mathrm{S}}=-0.61 \mathrm{eV} /$ atom for the heat of solution for tritium in $\mathrm{SiC}$ implies a trap binding energy of $\mathrm{QT}_{\mathrm{T}}=2.87 \mathrm{eV}$. Binding this strong must come from formation of covalent chemical bonds between the D and C or Si atoms. For comparison, Robell et. al. [12] obtained a value of $2.94 \mathrm{eV}$ for the for the $\mathrm{C}-\mathrm{H}$ bond energy from studies of surface diffusion of $\mathrm{H}$ on carbon. Myers et. al. [9] have recently determined a bond energy of $2.5 \mathrm{eV}$ for Si-D at silicon surfaces. Bond strengths in molecules are somewhat higher, ranging from 2.8 to $3.9 \mathrm{eV}$ for Si-H bonds in various molecular species [13] and 3.5 to $4.8 \mathrm{eV}$ for $\mathrm{C}-\mathrm{H}$ bonds in various hydrocarbons [14]. The large activation energy for diffusion $(1.9 \mathrm{eV})$ is also consistent with trap dominated diffusion where the time spent in the traps by $\mathrm{D}$ atoms is long compared to the time spent moving between traps.

A more accurate expression for the apparent solubility which allows for saturation of the traps is

$$
\mathrm{C}^{*}=\mathrm{N}_{\mathrm{T}} \mathrm{C} /\left(\mathrm{N}_{\mathrm{T}}+\mathrm{C}\right)
$$

where $\mathrm{C}^{*}$ is the concentration of trapped $\mathrm{D}, \mathrm{C}$ is given by equations 1 and 3 above, and $\mathrm{N}_{\mathrm{T}}$ is the concentration of trap sites. From the fact that the tritium retention continued to increase with increasing gas pressure and with decreasing temperature over the range of pressures and temperatures used in our study of tritium retention in undamaged $\mathrm{SiC}$ [1], we can infer that the traps were not saturated, i.e. $\mathrm{N}_{\mathrm{T}} \gg \mathrm{C}^{*}$. The measured apparent concentration of $\mathrm{D}$ in solution in undamaged $\mathrm{SiC}$ for the soak conditions used in the present study $\left(\mathrm{T}=1000^{\circ} \mathrm{C}\right.$ and $\left.\mathrm{P}=0.85\right)$ was $\mathrm{C}^{*}=2 \times 10^{18} \mathrm{~L} / \mathrm{cm}^{3}$ or 20 atomic ppm. A further point to note is that the prefactor for the apparent solubility $S_{O}$ must be proportional to the concentration of traps.

For the situation described above where trapping determines the effective solubility and diffusivity and where the traps arre not saturated, the apparent solubility is proportional to the concentration of traps and the apparent diffusivity is inversely proportional to the concentration of traps. The steady-state permeability, which is the product of the diffusivity and the solubility is therefore not affected by the trapping. In steady-state permeation the tritium in the traps does not 
change with time and is merely a spectator to the process. However, transient effects, such as breakthrough times and the thermal release, are affected by trapping.

We now consider what is known about the microstructure of the traps in the CVD SiC. For the reasons discussed above the traps are believed to be dangling bonds on $\mathrm{C}$ or $\mathrm{Si}$ atoms at defects in the lattice. Possible lattice defects irclude grain boundaries, dislocations, point defects such as vacancies or substitutional impurities, and surfaces (internal and external). The grain size in the samples used in this study was approximately $1 \mu \mathrm{m}$ on one side, and significantly larger than $1 \mu \mathrm{m}$ on the other side. This indicates a higher density of lattice defects and therefore traps on the side with the smaller grains. This is consistent with our NRA measurements of near surface concentrations of $\mathrm{D}$ in $\mathrm{SiC}$ samples exposed at $1000^{\circ} \mathrm{C}$ to $\mathrm{D}_{2}$ gas which showed that the side with smaller grains retained 2 to 3 times more $D$ than the side with the larger grains. This difference was consistently seen on several samples. The following calculation shows that the observed retention could be due to defects at grain boundaries. A cubic grain of size $d$ has a surface to volume ratio of $6 d^{2} / d^{3}$. Since each grain surface is shared by two grains the area of grain boundary per unit volume in bulk material is $3 / \mathrm{d}=3 \times 10^{4} / \mathrm{cm}$ for $\mathrm{d}=1 \mu \mathrm{m}$. Using a surface coverage of $10^{15}$ atoms $/ \mathrm{cm}^{2}$ yields a trap density of $3 \times 10^{19} / \mathrm{cm}^{3}$. This probably overestimates the trap density since many of the atoms at grain boundaries will not have dangling bonds. Trapping at grain boundaries can therefore account for the observed retained concentrations of $2 \times 10^{18} \mathrm{D} / \mathrm{cm}^{3}$.

\subsection{Efrect of Lattice Damage on Apparent Solubility}

The possibility remains that other types of lattice defects besides grain boundaries, such as dislocations or point defects within the grains, may contribute to D trapping. Defects of this kind are produced during irradiation by energetic ions or neutrons. Thus one might expect the $D$ retention or apparent solubility to be increased by ion irradiation. Trapping of $D$ at lattice damage occurs in metals [8], in silicon [9], and in graphite, [2] where a damage level of 0.04 DPA increases the $\mathrm{D}$ retention from $\sim 20$ to $\sim 600$ atomic $\mathrm{ppm}$, .

Figure 3 shows the concentration of $\mathrm{D}$ versus depth in the $\mathrm{SiC}$ samples after ion irradiation and soaking in $\mathrm{D}_{2}$ gas. For comparison the $\mathrm{D}$ profile is also shown for a sample (SIC3) which was soaked in $\mathrm{D}_{2}$ gas but not ion irradiated. Most of the samples had about $10^{15} \mathrm{D} / \mathrm{cm}^{2}$ at the surface indicated by the abrupt decrease in concencration between the surface and $0.2 \mu \mathrm{m}$. This amount of $\mathrm{D}$ is similar to the number of $\mathrm{SiC}$ atoms at the surface. This surface $\mathrm{D}$ appears to be unaffected by ion irradiation. The larger amount of D on the surface of SIC13 may be related to the molybdenum contamination discussed in section 2.4. Most of the samples had D concentrations of $20 \pm 10$ atomic ppm at depths of $2 \mu \mathrm{m}$ or greater. Samples with higher DPA near 


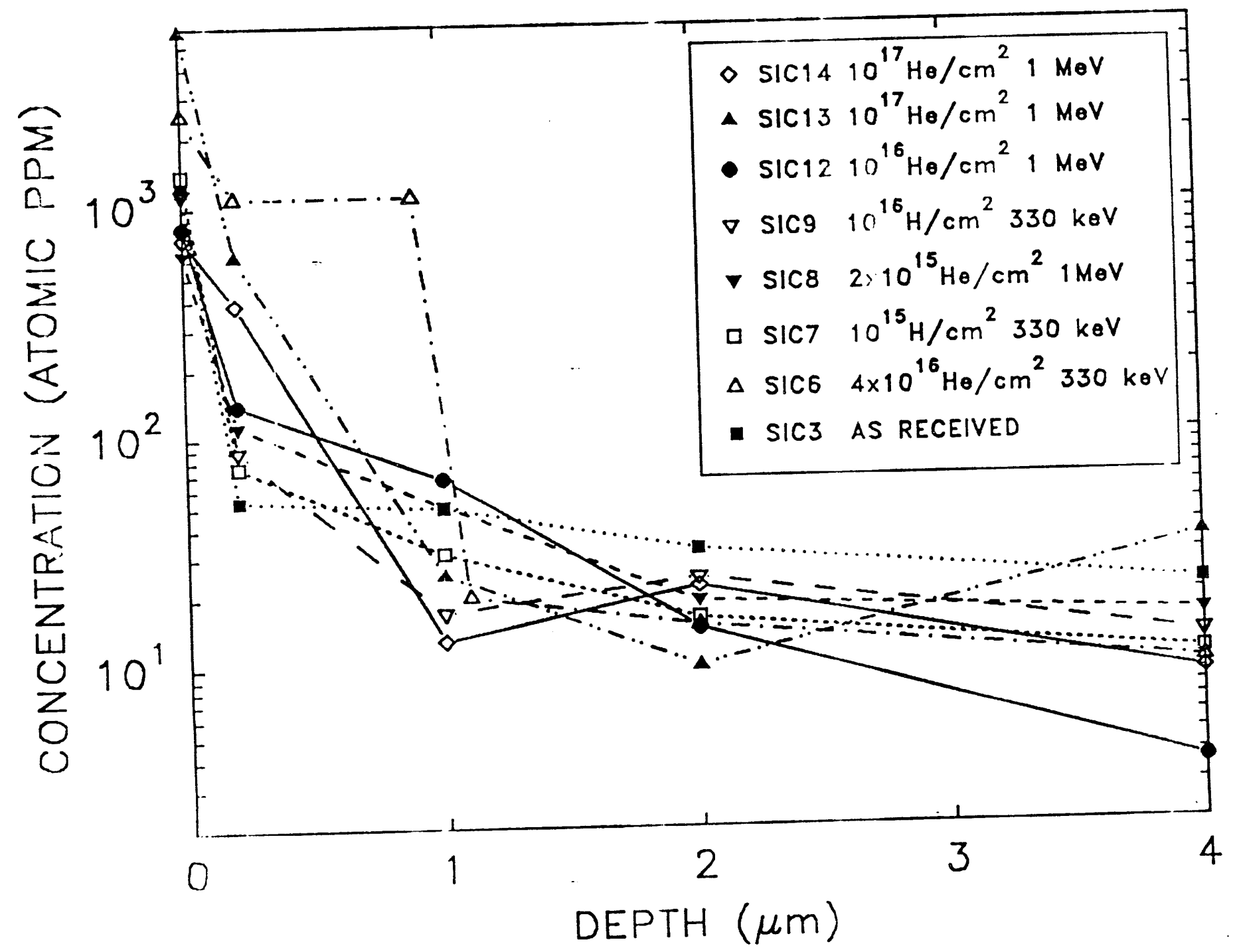

FIGURE 3 D Conceltration versus depth obtained by deconvuluting data from nuclear reaction analysis. 
the surface (SIC6, SIC12, SIC13, SIC14) had significantly more D at depths between $0.2 \mu \mathrm{m}$ and $0.5 \mu \mathrm{m}$ than the unirradiated sample. However a conspicuous feature of the data is the absence of any enhancement in the $D$ retention at depths near $2 \mu \mathrm{m}$ where most of the irradiated samples had the highest damage. Sample SIC6 showed an increase in the concentration of retained D, by a factor of about 20 compared to the unirradiated sample, to a depth of $1 \mu \mathrm{m}$ which was the EOR of the He irradiation for this sample.

Values for the $D$ concentration at $4 \mu \mathrm{m}$ are less precise than values closer to the surface for two reasons. Firstly, $4 \mu \mathrm{m}$ is near the limit at which $\mathrm{D}$ still contributes to the measured NRA yield at the highest analysis beam energy as can be seen in figure 2 . The sensitivity to $D$ at this depih is smaller, and the uncertainty in the $\mathrm{D}$ concentration at this depth is correspondingly larger, compared to D nearer the surface. Secondly, at the high analysis beam energies, the NRA yield from $D$ at $4 \mu \mathrm{m}$ is added to the yield from the much larger amount of $D$ nearer the surface. Thus small uncertainties in the amount of $D$ near the surface, due to scatter in the data, cause larger relative uncertainties in the small concentrations at $4 \mu \mathrm{m}$. For these reasons the apparant variations in $D$ concentration at $4 \mu \mathrm{m}$ between the various samples shown in figure 3 are not very significant.

Sample SIC17 was used to examine the thermal release of D implanted into SiC. This sample was implanted with $2 \times 10^{15} \mathrm{D} / \mathrm{cm}^{2}$ at $60 \mathrm{keV}$ producing a peak $\mathrm{D}$ concentration of about 0.2 atomic $\%$ at a depth of $0.5 \mu \mathrm{m}$. The sample temperature was then ramped up linearly in time at $5^{\circ}$ $\mathrm{C} /$ minute to $1000^{\circ} \mathrm{C}$ while the amount of $\mathrm{D}$ remaining was monitored by NRA. The heating produced no change in the amount of $D$ in this sample. This result indicates that transport of implanted $D$ to the surface is slower than predicted by the diffusion coefficient determined from the gas soaked undamaged $\mathrm{SiC}$.

\section{Conclusions}

Our experiments show that very near the surface $(<0.5 \mu \mathrm{m})$ the concentration of $D$ is larger in irradiated $\mathrm{SiC}$ than in the unirradiated material, but beyond $1 \mu \mathrm{m}$ the $\mathrm{D}$ concentrations were similar ( $20 \pm 10$ atomic ppm), even though the damage extended to $2.2 \mu \mathrm{m}$ in most of our samples. This result shows that lattice damage increases $\mathrm{D}$ retention in $\mathrm{SiC}$ but that permeation of $\mathrm{D}$ through the $\mathrm{SiC}$ to the damage is slower than was indicated by our previous measurements of tritium migration in undamaged $\mathrm{SiC}$. In a related experiment, $\mathrm{D}$ implanted into $\mathrm{SiC}$ was not released by heating to $1000^{\circ} \mathrm{C}$. This result shows that transport of implanted $\mathrm{D}$ to the surface is slower than predicted by the diffusion coefficient determined from the gas soaked undamaged 
$\mathrm{SiC}$. However this result is consistent with the slow release of tritium implanted into SiC observed in an earlier study [3].

A model for transport of $\mathrm{D}$ in $\mathrm{SiC}$ which is consistent with the above observations is that uptake of $\mathrm{D}$ from gas into undamaged $\mathrm{SiC}$ involves transport along grain boundaries, whereas uptake of $D$ into lattice damage produced by ion irradiation and release of energetically implanted $D$ both require transport of $D$ within grains which is much slower. Two observations support the conclusion that $\mathrm{D}$ moves rapidly along grain boundaries and slowly within grains. The first observation is that $D$ retention is not enhanced at the high damage region at the end of range in the iriadiated SiC. We take this as evidence that tiee $D$ cannot permeate far enough into the grains to reach the damage. Since the grain size is comparable to the range of the implanted ions, most of the damage sites are within grains and not at grain boundaries. The near-surface enhancement in $\mathrm{D}$ retention indicates that bulk permeation can reach only a few tenths of a micrometer into a grain which is not far enough to reach the high damage region. The second observation is that $D$ implanted into $\mathrm{SiC}$ is retained to much higher temperatures than $\mathrm{D}$ retained after exposure to $\mathrm{D}_{2}$ gas. This observation is consistent with the picture that $\mathrm{D}$ from gas exposures moves in and out along grain boundaries, whereas $\mathrm{D}$ implanted into $\mathrm{SiC}$ stops mainly within grains and therefore must diffuse through a grain before it can reach a surface or grain boundary and escape.

The results from our present study of ion irradiated $\mathrm{SiC}$ together with our previous study of tritium migration in undamaged $\mathrm{SiC}$ thus support the conclusion that uptake of $\mathrm{D}$ from gas into undamaged $\mathrm{SiC}$ involves transport along grain boundaries, whereas uptake of $\mathrm{D}$ into lattice damage produced by ion irradiation, and release of energetically implanted $\mathrm{D}$ both require permeation of $D$ within grains which is much slower. Based on this conclusion, the effectiveness of $\mathrm{SiC}$ films as a permeation barrier for tritium can be improved by increasing the grain size of the films. Finally, the fact that damage levels of several DPA had little effect on D retention at depths greater than $1 \mu \mathrm{m}$ indicates that neutron irradiation in a reactor may also have little effect on permeation of tritium through a SiC film. 


\section{References}

1. R. A. Causey, W. R. Wampler and J. R. Retelle, Tritium Migration in Vapor Deposited Beta Silicon Carbide, SAND92-8217 UC-504, (1992).

2. W. R. Wampler, B. L. Doyle, R. A. Causey and K. Wilson, J. Nucl. Mater. 176\&177 (1990) 983.

3. R. A. Causey, J. D. Fowler, C. Ravanbakht, T. S. Elleman and K. Verghese, J. Amer. Ceram. Soc. 61 (1978) 221.

4. J. F. Ziegler, J. P. Biersack and U. Littmark, The Stopping and Range of Ions in Solids, Pergamon Press 1985.

5. K. Nakata, S. Kasahara, S. Shimanuki, Y. Katano, H. Ohno and J. Kuniya, J. Nucl. Mater. 179-181 1991403.

6. K. Hojou, S. Furuno, H. Otsu, H. Izui, and T. Tsukamoto, J. Nucl. Mater. 155-157 (1988) 298.

7. K. Sasaki, T. Yano, T. Maruyama and T. Iseki, J. Nucl. Mater. 179-181 (1991) 407.

8. S. M. Myers, P. M. Richards, W. R. Wampler, and F. Besenbacher, J. Nucl. Mater. 165 (1989) 9.

9. S. M. Myers, D. M. Follstaedt, H. J. Stein and W. R. Wampler, Phys Rev. B $\underline{45}$ (1992) 3914.

10. W. Möller and F. Besenbacher, Nucl. Instr. and Meth. 168 (1980) 1111.

11. S. M. Myers, G. R. Caskey, D. E. Rawl and R. D. Sisson, Metall. Trans. A 14A (1983) 2261.

12. A. J. Robell, E. V. Ballou and M Boudart, J. Phys. Chem. $\underline{68}$ (1964) 2784.

13. R. Walsh, Acc. Chem. Res. 14 (1981) 246.

14. CRC Handbook of Chemistry and Physics (1974) R. C. Weast (ed.), CRC Press, Cleveland. 


\section{Unlimited Release}

\section{Initial Distribution}

8000

8300

8347

8535

8700

7141

8523-2

8535
J.C. Crawford

W.J. McLean

R.A. Causey (50)

Publications Division

R.C. Wayne

Technical Library Processes Division (5)

Central Technical Files (3)

Publications Division for OSTI (10) 

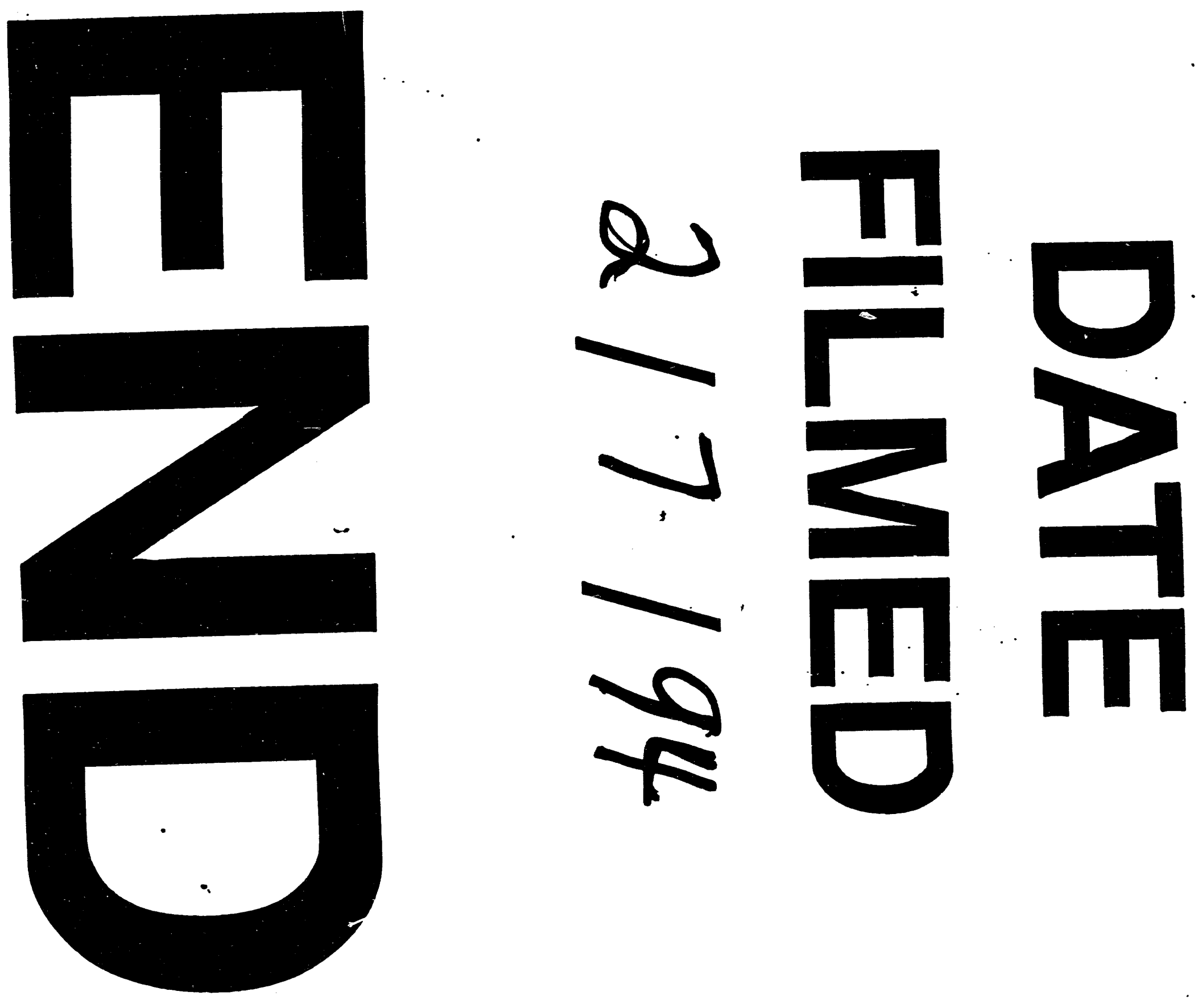
